\title{
7. The Change of Paradigm in the System of Education
}

\author{
Pier Cesare Rivoltella \\ doi.org/10.3280/oa-637-7
}

\section{Getting Rid of the Teacher's Desk}

Il paese sbagliato (the wrong country) is a book written by Mario Lodi (1970) dedicated to one of his former primary school pupils, Katia, who, after middle school, continued her studies in high school to become a teacher ${ }^{26}$. To this day, the programmatic title of this book stands out as a testimony to the great modernity of Lodi's reflection. As he noted, there are «analogies between the period immediately after the war and today [1970]. Like then, there is now a strong need to morally reconstruct our society by recovering abandoned values». His proposition to address this concern is to counter «the philosophy of consumerism and careerism» with «collaboration, cooperation, solidarity, nonviolence» (Lodi, 1970, p. XIX). Fifty years later, this analysis is still perfectly relevant and in tune with the theme of this paper, which proposes a political vision for the schooling system and education. Herein we propose to counteract a logic of consumerism and competition with that of communitas and participation, or, following Martha Nussbaum's categories, an education grounded in democracy to contrast an education geared towards profit (Nussbaum, 2010). In his introduction to the book, entitled Letter to Katia, Lodi wrote:

I find myself in the middle of the classroom. In addition to the cupboard, the podium on which my desk is placed, the flipping blackboard, and the gas stove, there should be space for individual small desks with suitable chairs, a table, and a wardrobe for the children. I tried again and again to reorganise the students' desks in different ways, but regardless of how I arranged them, they would still obstruct the children's movements. If worse comes to worst, my desk will have to go, as it serves no purpose, and the cupboard as well can be moved to the corridor [...].

\footnotetext{
${ }^{26}$ In those years, the four years of the "Magistrale" high school were still sufficient to become kindergarten and primary school teachers (the latter, at that time, was still called elementary school). From 2000 onwards, the new university Courses in Primary School Education (initially a four-year program and then a five-year program) became a requirement to teach to those age groups analogously to the requirements already in place for secondary school teachers.
} 
And what about the podium? I have an idea! It can be pushed against the wall, below the blackboard, it will be our... little stage or, better yet, the little piazza where the public gatherings of our small community will take place. I used to bump into it when I was walking through the classroom as it was hidden by the desks, but I have decided not to get rid of it because that square metre of social space, where the children will have the opportunity to sing, play, tell stories and paint, is the most important piece of furniture of all (Lodi, 1970, p. 17).

We are facing a paradoxical situation in which the children cannot fit, because the classroom seems to have been designed for the furniture and not for the students: as it is the case with many institutionalised spaces, this classroom suffers from rigid, constraint-based regulations. Lodi choses to value the children's needs above the traditional use of this space, and that is why the desk has to be taken out of the room. It is a very dramatic and bold action this «taking the desk off stage»: «getting rid of the teacher's desk which serves no purpose». This physical removal of the desk from the classroom constitutes an abandonment of a teacher's symbol of power and of a specific way of conceiving the school system and education. Conversely, the podium can stay, because it can be turned into a «stage» and a «social space» for the teacher and his pupils alike. The podium is the «most important piece of furniture» because the children can become protagonists. Lodi is a member of the Movimento di Cooperazione Educativa (movement for educational cooperation) that introduced in Italy the techniques of Freinet, one of the masters of the Movimento delle Scuole Nuove (movement of the new schools $)^{27}$. That movement was developed around the idea that the didactic relationship should be turned around: the classroom should not be an auditorium but a laboratory/workshop, where the cooperation between teachers and students is paramount.

This way of rethinking the classroom centres around the desire to reconnect schools with everyday life. The school is an artificial space, where traditionally one learns through symbolic intermediaries (Damiano, 1999) such as writing and other notations (mathematical symbols for example).

27 The Movement was founded in 1951 in Fano. Giuseppe Tamagnini, Aldo Pettini and Margherita Zoebeli were its inspirers, and notable members were Anna Marcucci Fantini, Danilo Dolci and Mario Lodi, all elementary school teachers and all enticed by the techniques that the école Freinet developed. Convinced of the centrality of the child and of the importance of the active methods, the Movement has recently found interesting interpreters in teacher Franco Lorenzoni's home-laboratory in Cenci (Lorenzoni, 2014), and in Marco Orsi, a school director who, inspired by Freinet's ideas, outlined the method of the Scuola Senza Zaino (school without backpack, see Orsi, 2016). For a retrospective reconstruction of the MCE in Italy, see Rizzi, 2017. 
These intermediations are far removed from life, which offers different experiences and follows different logics. To transform the classroom into a workshop or a laboratory constitutes an attempt to bring life back "into" the schools, to make meaningful what happens inside the classroom precisely because it has a real connection with life experiences.

Central to this rethinking of school and life, is the role of the podium which has become the «stage» for both teachers and students. Lodi is not comparing the stage to an end-of-the-year show for parents and families to enjoy; rather, he is thinking about it in terms of a «social space», an arena where the active participation of the students can blossom, empowering them to grow little by little into citizens. This idea is connected to his belief that the classroom is a "school cooperative", a training camp for democracy, which gives to teachers and students the tools and spaces to fight for their rights. This way of thinking is very similar to what Don Milani was experimenting in the School of Barbiana $^{28}$ around the same years.

These three key-concepts - the school as a workshop, the reconciliation between school and everyday life, and the school as a social space - bring the school very close to the theatre. Let us think for example about Grotowski's or Barba's training and theatre-laboratory, Artaud's theories, the anthropology of performance and the social function of the theatre: these are analogies, not just similarities.

\section{School, Theatre and Writing}

Derrick de Kerckhove, McLuhan's successor and director of the McLuhan Project at the University of Toronto, through an investigation of these three analogies, discusses the relationship between theatre and the transition from orality to writing; he writes:

In short, the difference between incarnation and imitation, interiorisation and exteriorisation, is the same that distinguishes the proprioceptive mimesis of the minstrel (aoidós) and the imitative acting of the actor. When Grotowski demands the actor to live his role with every muscle of his/her body, when Artaud requests that the play should feel like a dentist's appointment, they both expect the impossible: that the actor can find him/herself in the same conditions as the minstrel, for whom the known things were inseparable from the lived ones. A minstrel is an actor in a trance $(1990$, p. 69$)$.

${ }^{28}$ In the last pages of Il paese sbagliato, Lodi mentions his visit to Barbiana in 1961 and the meeting with Don Milani and his boys. They started a correspondence between their classes: another technique inspired by Freinet and aimed at building citizenship through literacy. 
However, as soon as he understands that there could be a relationship between theatre and the minstrel's performance, de Kerckhove does not further develop this concept, abandoning it in support of the erroneous thesis that traces back the genesis of the theatre to writing instead of orality. First of all, according to de Kerckhove, what theatre and writing have in common is the order of vision. This is proven by the fact that the theatrical lexicon refers explicitly to sight and not to hearing: the theatre is the place where one goes to see (théatron), confirming that the Greeks invented visual space. Spectators, indeed, are invited to concentrate their attention on what happens on stage and, thanks to visual perception, they can summarise what they see. De Kerckhove adds:

it is only the theatre that made us into spectators in the strict sense of the term. All other media force us to change constantly point of view and consequently to create bonds and cognitive relationships between the different planes and points of view of the filmed sequences [...]. Even our habit to read teaches us from infancy to see the world from one point of view (ibid., pp. 76 and 77).

Secondly, exactly in the same manner in which writing separates the meaning of words from the code that conveys it, the theatre separates the public from the action. A similar situation is experienced when, while reading, we soon forget about the materiality of the pages of the book we are holding in our hands because we are completely transported into the narration; or when at the theatre we feel as if we were transported into the play forgetting to be seated in a theatre. This is what de Kerckhove calls «transparency of the code», which is clarified through the concept of the «double articulation» (de Kerckhove, 1991) of writing. The visual perception of the individual graphemes that make up the word and their perceptive organisation in a sequence, generates a «mental sound» that in the long run no longer needs to pass through the representation of the corresponding object (first level of articulation) in order to be understood, while «skipping» directly to the abstract meaning (second level of articulation):

it was the theatre itself that encouraged, after the development of writing, our inclination for abstractions. It was in the theatre that we began to cultivate this typically Western ability to abstract meanings (signification) from the senses (sensitive). It seems that the theatre was developed to accelerate these tendencies towards desensorialisation, teaching us to separate the body from the mind (de Kerckhove, 1990, p. 71). 
The conclusion of this reasoning is relevant to education. Following de Kerckhove's theorisation of the origins of theatre from writing, it «is the place of education and of the centralisation of the gaze». Training the eye is a recurring obsession in the history of Western education. According to the ancient Greeks, being able to see enables to discern the truth. This belief can be explained by the centrality that visual culture holds in ancient Greek culture; even from a linguistic point of view, knowledge is categorised in terms of vision (as clearly proven by the aorist oida of the verb orào: "I have seen" and therefore "I know"). This principle carries through to Christian culture where it becomes charged with spiritual and ethical values. According to the Early Church Fathers, the gaze is a symbol of providence, chastity and faith. In the mystic tradition - let's take for example Hildegard of Bingen, Francis of Assisi, Richard of St Victor - sight is an instrument of the visio estatica. From the first centuries of the Christian era, "to take a look" acquires the educational meaning of consoling, urging, caring for. From the Middle Ages onwards, moreover, the concupiscentia oculis increasingly came to denote the concupiscentia cordis. Sins occur mainly through the eyes and it is no coincidence that a significant part in the education of young girls was achieved by teaching them from an early age "how to look around them". This is the case reported in a paper written at the end of the $14^{\text {th }}$ century - le Ménagier de Paris - in which a man in his sixties illustrates the recommendations he gave to his 15 -year-old wife on proper behaviour, which required her to keep «her eyes down [...] without looking around, without looking up and without peeking here and there» (Giallongo, 1995, p. 218).

The theatre does not only educate the gaze, it also facilitates its centralisation. This is made possible by the spectatorial dispositif: someone is on stage, speaking, communicating, moving around, someone else is in the stalls, watching. Silence and attention play a cardinal role in this situation, apparently favouring concentration instead of participation.

We find here the distinctive elements of the school dispositif (Rivoltella, 2019), as Foucault described it in Discipline and Punish (1975): surveillance (of the students' absences, behaviours, movements in the school premises, attention paid to lessons) and sanctions (their grades, track records, the disciplinary reprimands, suspensions, postponements and rejections) (Massa, 1986; Cappa, 2009). If de Kerckhove is right and theatre stemmed from writing, and if its aim, as his analysis suggests, is to educate and focus the gaze, then in this notion of theatre one can find the same obsessions that are at the base of some traditional forms of education, those that Mario Lodi contested when he pushed the teacher's desk into the corridor. In brief, this understanding of theatre and schooling would be functional to socialisation, 
cultural reproduction and the preservation of the status quo. The symptoms of this common destiny are clearly detectable:

- the primacy of the dramatic text and the centrality of the textbook;

- the one-way communication between actors and their public and teachers and their students;

- the orientation of the point of view and the didactic suggestion of what must be emphasised and held in high consideration;

- the institutionalised space (the theatre or the classroom) as a socially constructed place;

- the word disconnected from the body and the teacher's "blabbering", which, according to Paulo Freire (1970), describes a manner of talking that is devoid of concreteness and agency, typical of those teachers who are not interested in developing critical thinking but in reinforcing oppression and exclusion.

\section{The Total Technology of the Word}

Eric Havelock (1963) and Walter Ong (1982) are both renowned for their studies on the development of Western culture and on the process of alphabetisation that sees the transition of mankind from orality to writing. Havelock's work can lend some evidence that helps to radically rethink the perspective briefly exposed in the last paragraph.

First of all, it is clear from Havelock's description that the storytellers' performance in Homeric Greece was a "place of education", well before writing and the codification of canonical theatrical space. This is something that is hard for us to understand, since the experience we have today of those Homeric songs is mediated by their transcriptions - which took place between the $7^{\text {th }}$ and $6^{\text {th }}$ centuries B.C. - and this has created a gap between the celebrated deeds of those ancient heroes and us, a distance that is not merely temporal but also cultural. That type of singing is nowadays only experienced in middle and high school, when reading a few dactylic hexameters from the Iliad and the Odyssey in the original Greek, which is actually mixed with ionic and aeolian dialects, proof of the gradual transition from the oral tradition to the written text. This experience is rarely exciting for students. Epic, as a school subject, reduces Homeric poems to repertoires of names of characters and to their narratively complex events that students are asked to summarise and draw a profile of, which proves to be a difficult task to accomplish given the temporal and cultural distance from today's children. On the other hand, at high school level, the students' brief encounter with a few passages in the original language, is more often reduced to a grammatical and syntactical hurdle or a first encounter (also not very 
pleasant) with metrics, rather than being a real opportunity to understand a significant moment of early Western culture.

On the other hand, everything changes if we think that the deeds of the heroes before being captured on paper were handed down orally for centuries. The interest that the Greeks had towards these deeds was not narrative or "literary", but functional and bureaucratic (Graff, 1981). As Havelock puts it, Homer's poems were the encyclopaedia of the Greek people, a massive repository of actions, maxims and useful knowledge instrumental to the transmission of the ethos and nomos: habits and customs, practical rules, and rules of civil coexistence. Singing those deeds and teaching them to the younger generations was, therefore, something more akin to schooling than to performance. If those deeds had not been handed down, the very culture of the Greek people would not have been passed on, which would have led to the death of their civilisation. Moreover, in an oral civilisation, the only way to ensure this transmission was through the repetition of the songs sung by the storytellers.

How did these stories produce learning? How can we imagine the performance of the storyteller? Plato supplies an answer to these questions in his reprimanding of poetry and theatre for fostering learning by imitation, through mimesis, implying that it was, for this very reason, a "light" form of learning, not based on the rational understanding of the concept. Thus, he hinted, when the storytellers sang the heroic deeds, they would fall into the same state of trance mentioned by de Kerckhove ${ }^{29}$.

The technology of memorisation as exploited by the minstrel will seem unfamiliar to us, for we have long been accustomed to dispense with it. [...] The Homeric audience submitted gratefully to the hypnotism of another. The situation most comparable to the Greek would in our modern culture be found in the effect upon the popular memory of verses which are wedded to popular melodies and recorded and played on machines. Particularly close is the analogy provided by Jazz and other dance rhythms so far as these are often married to words which are then remembered (Havelock, 1963, pp. 146 and 147).

Let us think about what Havelock suggests: the storyteller's performance is at the same time a spoken word and movement (analogy with dance) and is

\footnotetext{
${ }^{29}$ It is a fact that Plato's relationship with poetry, and more generally with art, is controversial. The rejection and ostracism of poetry/art from his Ideal City in the Republic is more a debt paid to the rational logic with which he constructed his politics, which is consistent with the assumptions of his metaphysics rather than with the result of a convinced adhesion. For an indepth analysis of Plato's relationship with art, see Melchiorre, 1986.
} 
accompanied by music (analogy with jazz). Havelock says that the listeners were:

bombarded simultaneously by two disparate sets of sounds organised in a concordant rhythm: the metrical speech and the instrumental melody [to which was added the rhythm of] the legs and feet and their motions as organised in dancing (Havelock, 1963, p. 150).

The result is learning based on a globality of perception, capable of activating all the senses of the audience, who:

either [...] do this themselves in recitation, or they watch it being done, in which case the mnemonic assistance is mediated to them through the eyes, as they watch the dance rhythm, and perhaps as they watch their nervous systems respond sympathetically with small concealed motions of their own without necessarily agitating the legs. [...] The entire nervous system, in short, is geared to the task of memorisation (ibid., pp. 150 and 151).

At least two important considerations can be drawn from these observations. First of all, it is clear that Homeric minstrels were proto-actors. We can imagine them while they tell stories - similarly to the storytellers of our tradition and to the African griot (Fadonougbo, 2007) - modulating the tone, timbre and pitch of their voice, moving in space, accompanying their actions with the lyre (the griot with the drum), working with facial mimicry, exploiting the space's proxemics. All this was already theatre, long before the advent of alphabetic writing.

The second consideration stems from Havelock's hint to the neurophysiologic results of his analysis, extraordinarily advanced compared to the neuroscientific findings of his time. When the spectators watched the minstrels' performance, they moved with them, «respond[s/ed] sympathetically» as Havelock underlines. Against this backdrop, it is hard not to think about the function of the human mirror system (Rizzolatti and Sinigaglia, 2006 and 2019), or the importance of this discovery to explain human learning (Gallese and Guerra, 2015), or the insights achieved by the theories of the anthropology of performance developed by Schechner (2002a), Barba (1994) or Turner (1989). Knowledge is, according to Gallese and Guerra (2015), to perform or mimic within one's own body what is being observed, through the activation of the same neuronal system that would be activated if one was performing the same action. The action, or deed, consistent with the concept of embodiment, is not only the executor of what our brain decides, but also the space where our knowledge is produced. This 
is an utterly radical conclusion: the idea of a theatre which aims to capture the spectators' gaze and expects them to be concentrated in silence with their eyes fixed on the scene, leaves the place to a theatre that makes the body vibrate and that builds knowledge through bodily movements.

All that remains to be done is to retrace all of these ideas and identify the ways in which they can impact our understandings of schooling and education.

\section{A Provisional Conclusion. The Teacher-Actor}

From what we have thus far seen, it is clear that the Homeric minstrel is not only a proto-actor, but also a proto-teacher. Theatre, schooling and education all stem from orality. Through this understanding, theatre and education cannot be distinguished one from the other: theatre is education and education is theatre. If this holds true, then the minstrel is also a teacher, a teacher who does not just care about the students' minds but also attends holistically to their mind-body-brain system. This way of thinking is not usually encouraged within traditional didactics, which understands teaching as a design science (Laurillard, 2012) that prioritises the designing of projects, the planning of future actions, and the preparation of teaching materials over situated action. It is necessary to rethink teaching as an «art of life», following Jean-Marie Pradier's definition (Rivoltella, 2017). Three quick thoughts can help understand the meaning of this process.

First of all, if teaching is an art of life, its agency must centre on voice and body movements. A new training method should be devised both for novices and experienced teachers which, instead of focusing on discussing behaviours, should emphasise their cortical appropriation, as it is taught in acting school. Such embodied training would prepare teachers to become more attuned with their bodies and thus able to develop stronger connection with their students. This training will also enable teachers to balance theory and practice, conceptualisation and action.

Secondly, rethinking teaching as an art of life makes class work similar to writing a script: a choral dramaturgy where the most important skills are the ability to "be aware" of the group, to create the appropriate generative environment for the group, and to use feedback to keep the structural coupling with the students in constant balance. The discoveries of enactivism (Rossi, 2011) and the theory of action (Durand, 2015) provide interesting insights on this perspective.

Finally, the teacher-actor is also a teacher-director, with whom the class produces culture similarly to the way in which Renaissance festivals were staged (Francastel, 1951 and 1967). The work is divided into three main actions: the first step is to identify the cultural elements that one wishes to 
work on; these elements must be selected from everyday life and mainstream culture. The second step is to take these elements into the classroom/laboratory where they can be reassembled giving them new meanings. Lastly, the achieved new assemblage of cultural objects is reintroduced in mainstream culture. This is a political act, as schoolwork always inevitably is.

Mario Lodi's book ends with the memory of an evening theatrical performance in the middle school gymnasium in June 1969. Lorena, one of his students, sings and plays "on command» as he would have never wanted to see her do. He remembers her in first grade and does not recognise her anymore. Lodi writes,

I return home with great sadness and listen to Lorena's tapes in the silence of the night. I am under the impression that a crime has been committed. I think of how many similar crimes are committed in the schools that conform to the system and gather consensus through coercion. The aim of these schools is not to foster free children, nor happy men. To defend men means to be on their side and thus to rebuild the school, the system, and everything else (Lodi, 1970, p. 468). 